\title{
Study preferences in anatomy education: a descriptive study including preliminary results *
}

\author{
Ekremcan Karaer ${ }^{1}$, Çağatay Barut ${ }^{2}$ \\ ${ }^{1}$ School of Medicine, Bahçeşehir University, Istanbul, Turkey \\ ${ }^{2}$ Department of Anatomy, School of Medicine, Bahçeşehir University, Istanbul, Turkey
}

\begin{abstract}
Objectives: In anatomical education, there is a lack of consensus about the best or most efficient method used. Additionally, the learning style of students varies, and information related with the medical students' preferences for learning anatomy is rather limited. Thus, this article aimed to identify the study preferences of medical students in Turkey.

Methods: Ninety-seven medical students aged between 19-26 years participated in the study. Participants were asked 16 questions related with the education system and study preferences of anatomy. Nine of the questions were related with the education system of their school in general and in terms of anatomy and seven of the questions were related with their way of studying anatomy, including time spent for studying, preference for a group or individual study, study materials and methods.

Results: $88.6 \%$ of the respondents indicated that integrated medical education was the education system used in their schools. Systematic anatomy was the main method (93.8\%) chosen for anatomy. Plastic models were the most frequent preference for lab studies (90.7\%) followed by prosections (58.8\%), specimens (30.9\%) and cadaver dissections (21.6\%). Majority of the respondents preferred studying anatomy alone (86.6\%). Furthermore, students stated their preference of study methods as one or more at the same time, and the distribution of these methods were as follows: correlation of structures with relations (53.6\%), functions (52.6\%), clinical situations (30.9\%), memorizing with mnemonics (53.6\%) or tables and lists (45.4\%), flash cards (7.2\%), and regular repetitions (40.2\%).
\end{abstract}

Conclusion: Study preferences may lead changes in anatomy curricula in the future.

Keywords: anatomy; dissection preference; study

Anatomy 2017;11(2):99-103 @2017 Turkish Society of Anatomy and Clinical Anatomy (TSACA)

\section{Introduction}

Many variations have occurred amongst the tools of anatomy education since the time Greek physician Herophilus of Chalcedon performed the first scientific dissection in the early part of the third century BC. Particularly with the influence of developing technology, dissection has had increasing alternatives in this journey. These diversified methods of teaching have been classified essentially into following categories: dissections made by students; inspec- tion of prosected specimens; didactic teaching; use of models; use of computer-assisted learning (CAL); slides and tapes; and teaching of living and radiological anatomy. ${ }^{[1-4]}$

Different students learn anatomy in different ways. ${ }^{[1-17]}$ Some students prefer learning in pairs, trios or even larger groups. ${ }^{[3,8,18]}$ However, some students rarely turn to their peers for help, working happily as individuals. ${ }^{[3]}$ On the other hand, selecting the method of studying is the main thing that shapes the study preferences of a student. Within

*This study was presented in the 111th Annual Meeting of the Anatomische Gesellschaft, 21-24 September 2016, Göttingen, Germany; and the National Medical Education Symposium (UTES), 15-17 March 2017, Antalya, Turkey. 
the observation of numerous students and educational sources, these diversified methods of studying have been classified essentially into following categories: correlation of adjacent structures; correlation made with clinical or functional knowledge; studying with anatomy games; studies made on cadavers; studying topics in small pieces; memorization with codes, tables, lists or flash cards; regular repetition of the studied subject.

Researchers trying to find the "ideal" method for anatomy education were mostly focused on what is the best teaching method for students, and finding the best studying method for studying anatomy has remains nearly unexplored. Thus, this study aims to evaluate the importance of study methods in student's success and determine the most preferred study method.

\section{Materials and Methods}

Ninety-seven medical students aged between 19-26 years participated in the study. A structured questionnaire was prepared using Google Forms. All of the participants were invited to complete the questionnaire via e-mail or social media (Facebook, WhatsApp etc.). Participants that did not respond to the required ques- tions of the survey were excluded from the study. The Ethics Committee of Bahçeşehir University endorsed its approval for the study.

The contents of the survey were divided into three parts: (i) socio-demographic characteristics of the participants, (ii) education system of participants' medical school and structure of the anatomy education, and (iii) study preferences for anatomy. Participants were asked five questions related with socio-demographic characteristics, followed by 16 questions related with the education system and study preferences of anatomy (Table 1). Nine of the questions were related with the education system of their school in general or in terms of anatomy and the rest of the questions were related with their way of studying anatomy including time spent for studying, preference for group or individual study, study materials, and study methods. Descriptive statistics for categorical variables were given with frequency and percentage.

\section{Results}

Students from various medical schools of Turkey answered the survey. $68.8 \%$ of these respondents were

Table 1

Questions related with education system and structure of the anatomy education and study preferences for anatomy.

\begin{tabular}{|c|c|}
\hline Anatomy in the medical school & Study methods \\
\hline What is the educational system of your medical school? & How much time do you spend on studying anatomy? \\
\hline $\begin{array}{l}\text { What kind of educational methods are used in the anatomy } \\
\text { courses of your medical school? }\end{array}$ & How do you prefer studying anatomy? \\
\hline $\begin{array}{l}\text { Please rank your chosen methods, starting from one, } \\
\text { with one being the most preferred. }\end{array}$ & $\begin{array}{l}\text { Please rank your chosen study preferences, starting from one, with one being } \\
\text { the most preferred. [(Study groups: More than } 2 \text { people }-2 \text { people) - Alone] }\end{array}$ \\
\hline $\begin{array}{l}\text { What is the duration of the anatomy course in your medical } \\
\text { faculties curriculum? }\end{array}$ & What kind of study sources are you using during your anatomy studies? \\
\hline $\begin{array}{l}\text { Considering the the selected time period above; please distribute the } \\
\text { anatomy topics that have been systematically separated below, according } \\
\text { to the year they are covered/going to be covered, from the table. } \\
\text { [If your anatomy education is still not finished in your school; and due to this, } \\
\text { if you have no information about someof the topics, please choose the } \\
\text { "star }\left({ }^{*}\right) \text { " option for them.] }\end{array}$ & $\begin{array}{l}\text { Please rank your chosen study sources, starting from one, with one being the most } \\
\text { preferred. [Textbooks - Notes that have been prepared by the lecturer - Notes that } \\
\text { have been taken during the lecture by yourself - Anatomy Channels - Websites - Atlases] }\end{array}$ \\
\hline $\begin{array}{l}\text { How is the distribution of theoretical lectures to practicals in the anatomy } \\
\text { courses of your medical school? }\end{array}$ & What kind of methods do you use during your anatomy studies? \\
\hline What kind of teaching method is used mainly in your theoretical lectures? & $\begin{array}{l}\text { Please rank your chosen study methods, starting from one, with one being the most } \\
\text { preferred. [Correlating with clinical knowledge] [Correlating adjacent structures] } \\
\text { [Correlating with functional knowledge] [Studying with anatomy games] [Studying from } \\
\text { cadavers] [Studying topics in small pieces] [Memorizing with codes] [Memorizing wit } \\
\text { tables or lists] [Memorizing with flash cards] [Repeating the study regulary] }\end{array}$ \\
\hline \multicolumn{2}{|l|}{ What kind of tools are used in your practical sessions? } \\
\hline $\begin{array}{l}\text { Please rank your selected tools, starting from one, with one being } \\
\text { the most preferred. [(Cadavers: Dissection - Prosection) - } \\
\text { Models Plastinated samples - Sections - Specimens] }\end{array}$ & \\
\hline
\end{tabular}




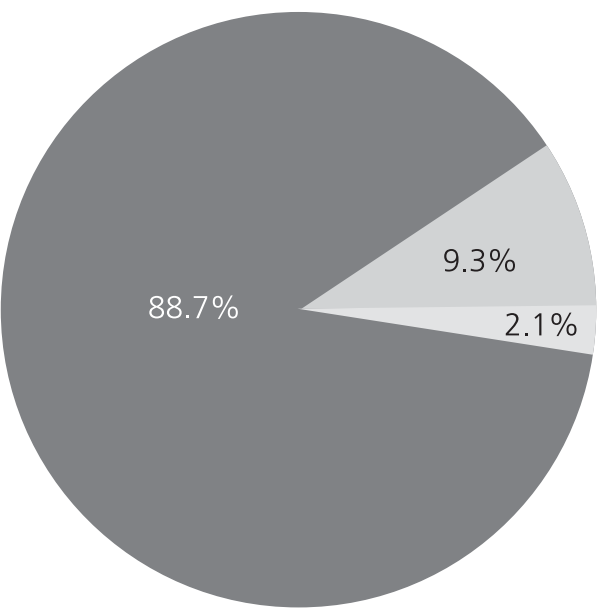

\begin{tabular}{|lcl|}
\hline & $\mathbf{n}$ & $\%$ \\
\hline Classical medicine education & 2 & 2.1 \\
Integrated medical education (Cummittee system) & 86 & 88.6 \\
Modern medical education (PBL system) & 9 & 9.3 \\
Other & 0 & 0 \\
\hline
\end{tabular}

Figure 1. Distribution of medical education systems of the medical schools among the participants.

first year students and $8.3 \%$ were second year. Rest of the respondents was 3rd-6th year medical students (22.9\%).

$88.6 \%$ of the respondents indicated that integrated medical education was the education system used in their schools (Figure 1). Systematic anatomy was the main method (93.8\%) chosen for anatomy education. Topographic anatomy (42.3\%), clinical anatomy $(41.2 \%)$ and radiological anatomy $(33 \%)$ were also present within the curricula of the schools (Figure 2).

$52.6 \%$ of the respondents indicated that anatomy classes were spread through two years of the curriculum, while $25.8 \%$ stated that the anatomy classes were spread through three years of the education (Figure 3).

$38.1 \%$ of the respondents stated that $70 \%$ of the classes were theoretical classes and 30\% were lab hours.

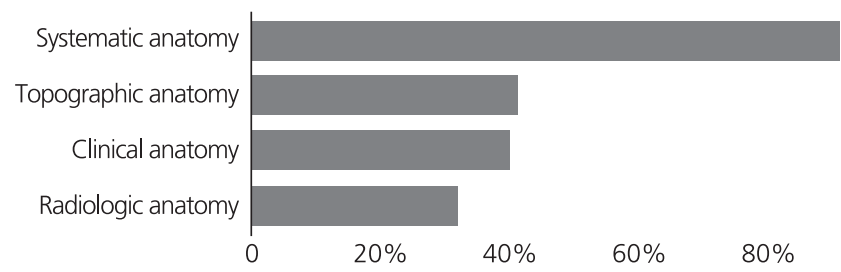

Figure 2. Distribution of anatomy methods within curricula of medical schools.

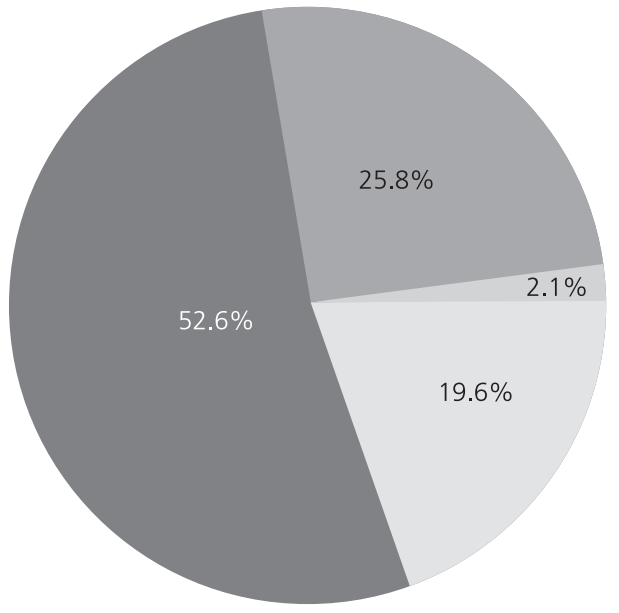

\begin{tabular}{|lcl|}
\hline & $\mathbf{n}$ & $\%$ \\
\hline 1 year & 19 & 19.6 \\
2 years & 51 & 52.6 \\
3 years & 25 & 25.8 \\
More than 3 years & 2 & 2.1 \\
\hline
\end{tabular}

Figure 3. Distribution of anatomy classes within the whole curriculum

Rest of the respondents indicated that the distribution of lab hours was between $45 \%$ and 50\% (Figure 4).

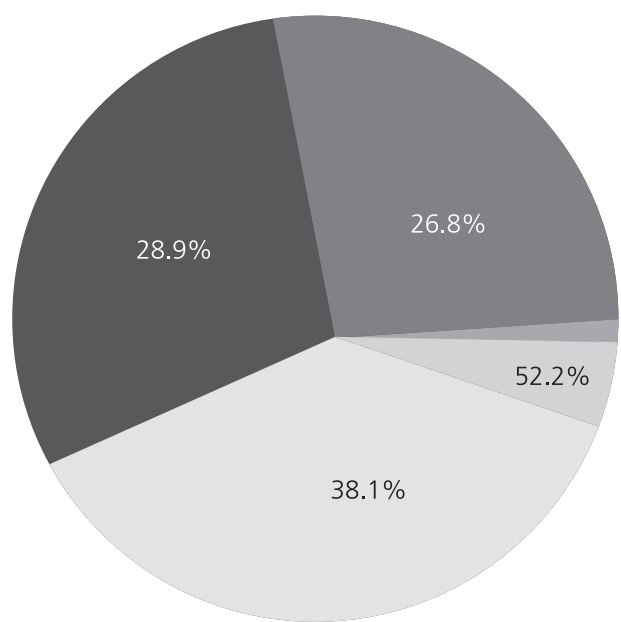

\begin{tabular}{|lcl|}
\hline & $\mathbf{n}$ & $\%$ \\
\hline Theoretical $100 \%$ - Practical $0 \%$ & 0 & 0 \\
Theoretical $85 \%$ - Practical $15 \%$ & 5 & 5.2 \\
Theoretical $70 \%$ - Practical $30 \%$ & 37 & 38.1 \\
Theoretical $55 \%$ - Practical $45 \%$ & 28 & 28.9 \\
Theoretical $50 \%$ - Practical $50 \%$ & 26 & 26.8 \\
\hline
\end{tabular}

Figure 4. Distribution of theoretical and practical hours of anatomy among different medical schools. 


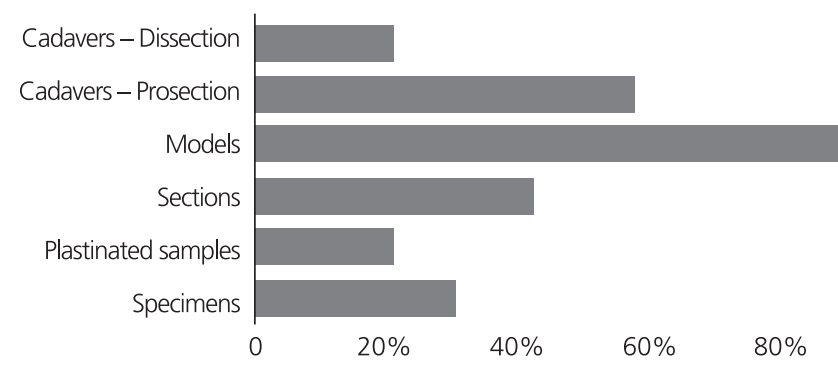

Figure 5. Preferences for lab studies.

Plastic models were the most frequent preference for lab studies $(90.7 \%)$, followed by prosections $(58.8 \%)$, specimens (30.9\%), and cadaver dissections (21.6\%) (Figure 5).

$41.3 \%$ of the respondents stated that time spent for anatomy studying was not less than 10-15 hours per month. Majority of the respondents preferred studying anatomy alone $(86.6 \%)$. But this was not the only preference. $29.9 \%$ of the students indicated that they also preferred study groups which were composed of 2 individuals (Figure 6).

Slide layouts of the theoretical class presentations were the leading preference for anatomy study sources (79.9\%). In addition to that, textbooks (61.9\%), web based anatomy videos $(55.7 \%)$ and anatomy web sites $(35.1 \%)$ were also other preferred sources. Moreover, it was a common sense that is difficult to study without an anatomy atlas (83.5\%) The students were able to prefer one or more of these sources at the same time (Figure 7).

The distribution of study methods were as follows: correlation of structures with relations $(53.6 \%)$, functions $(52.6 \%)$, clinical situations $(30.9 \%)$, memorizing with mnemonics $(53.6 \%)$, tables and lists $(45.4 \%)$ and flash cards $(7.2 \%)$, and regular repetitions $(40.2 \%)$. The students were able to prefer one or more of these methods at the same time (Figure 8).

\section{Discussion}

Study preferences in anatomy is an unexplored and crucial research field that has the potential to play an important role in the future of anatomy education. By letting students prefer one or more of study methods (correlation of

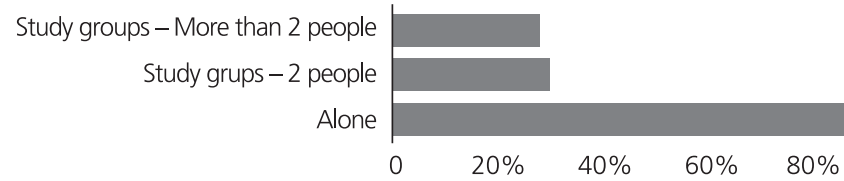

Figure 6. Distribution of the studying style among the participants.

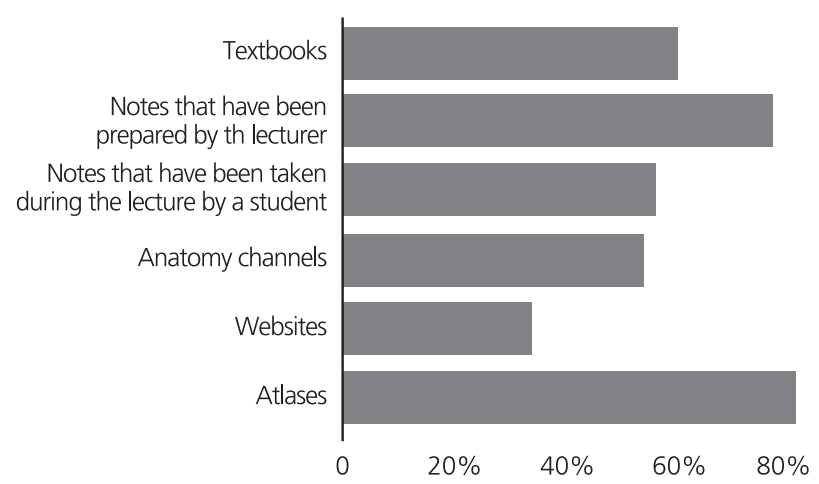

Figure 7. Distribution of sources for studying anatomy.

adjacent structures; correlation made with clinical or functional knowledge; studying with anatomy games; studies made on cadavers; studying topics in small pieces; memorization with codes, tables, lists or flash cards; regular repetition of the studied subject) at the same time and rank these methods according to their wish, this study expects to contribute to the important research field of study preferences. Due to the fact that it is still continuing, evaluation of statistical data was seen unnecessary in this article. Once the research is complete and all results are gathered, the statistical assessment shall be done.

\section{Conclusion}

Despite with only preliminary results, this descriptive study still shows a glimpse of that potential that study preferences may lead changes in anatomy curricula in the future.

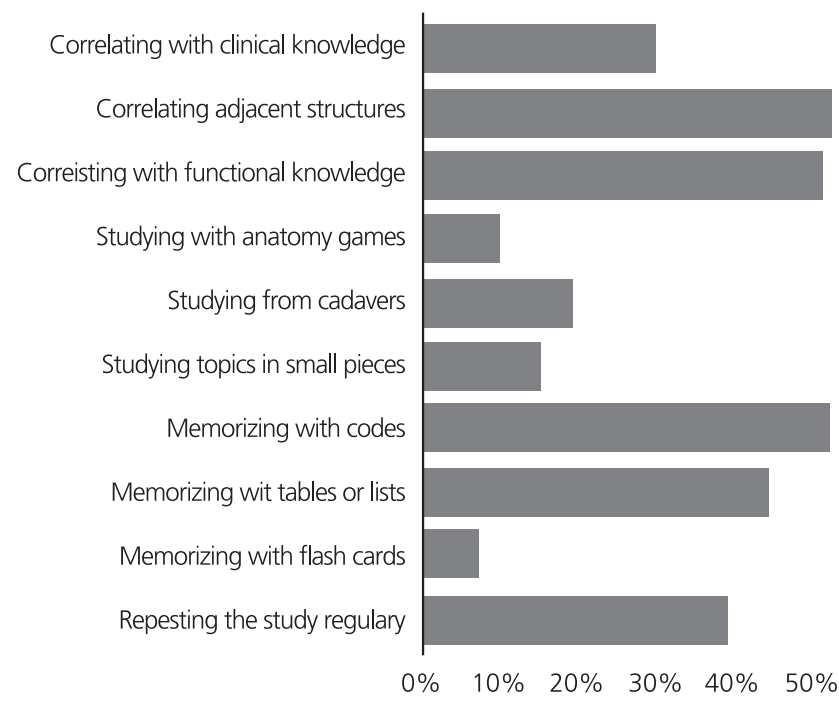

Figure 8. Distribution of the study methods of participants. 


\section{References}

1. Brenner E, Maurer H, Moriggl B, Pomaroli A. General educational objectives matched by the educational method of a dissection lab. Ann Anat 2003;185:173229-30.

2. Kerby J, Shukur ZN, Shalhoub J. The relationships between learning outcomes and methods of teaching anatomy as perceived by medical students. Clin Anat 2011;24:489-97.

3. Mitchell BS. Learning styles in anatomy teaching and learning. In: Chen LK, Pawlina W, editors. Teaching anatomy: a practical guide. 1st ed. New York (NY): Springer; 2015. p. 23-30.

4. Patel KM, Moxham BJ. The relationships between learning outcomes and methods of teaching anatomy as perceived by professional anatomists. Clin Anat 2008;21:182-9.

5. Anyanwu EG. Anatomy adventure: a board game for enhancing understanding of anatomy. Anat Sci Educ 2014;7:153-60.

6. Benninger B. Google Glass, ultrasound and palpation: the anatomy teacher of the future? Clin Anat 2015;28:152-5.

7. Buenting M, Mueller T, Raupach T, Luers G, Wehrenberg U, Gehl A, Anders S. Post mortem CT scans as a supplementary teaching method in gross anatomy. Ann Anat 2016;208:165-9.

8. Burgess AW, Ramsey-Stewart G, May J, Mellis C. Team-based learning methods in teaching topographical anatomy by dissection. ANZ J Surg 2012;82:457-60.

9. Donnelly L, Patten D, White P, Finn G. Virtual human dissector as a learning tool for studying cross-sectional anatomy. Med Teach 2009;31:553-5.
10. Fitzpatrick CM, Kolesari GL, Brasel KJ. Teaching anatomy with surgeons' tools: use of the laparoscope in clinical anatomy. Clin Anat 2001;14:349-53.

11. Fruhstorfer BH, Palmer J, Brydges S, Abrahams PH. The use of plastinated prosections for teaching anatomy - the view of medical students on the value of this learning resource. Clin Anat 2011;24:246-52.

12. Granger NA, Calleson DC, Henson OW, Juliano E, Wineski L, McDaniel MD, Burgoon JM. Use of web-based materials to enhance anatomy instruction in health sciences. Anat Rec B New Anat 2006; 289:121-7.

13. Jones DG. Re-inventing anatomy: the impact of plastination on how we see the human body. Clin Anat 2002;15:436-40.

14. Op Den Akker JW, Bohnen A, Oudegeest WJ, Hillen B. Giving color to a new curriculum: bodypaint as a tool in medical education. Clin Anat 2002;15:356-62.

15. Ruthenbeck GS, Carati CJ, Gibbins IL, Reynolds KJ. A virtual reality 3D jigsaw for teaching anatomy. Stud Health Technol Inform 2008;132:436-8.

16. Solyar A, Cuellar H, Sadoughi B, Olson TR, Fried MP. Endoscopic sinus surgery simulator as a teaching tool for anatomy education. Am J Surg 2008;196:120-4.

17. Winkelmann A, Hendrix S, Kiessling C. What do students actually do during a dissection course? First steps towards understanding a complex learning experience. Acad Med 2007;82:989-95.

18. Shankar N, Roopa R. Evaluation of a modified team based learning method for teaching general embryology to 1st year medical graduate students. Indian J Med Sci 2009;63:4-12.

Correspondence to: Çağatay Barut, MD, PhD Department of Anatomy, School of Medicine, Bahçeşehir University, Istanbul, Turkey Phone: +90 5324638471

e-mail: cagbarut@yahoo.com

Conflict of interest statement: No conflicts declared.

This is an open access article distributed under the terms of the Creative Commons Attribution-NonCommercial-NoDerivs 3.0 Unported (CC BY-NCND3.0) Licence (http://creativecommons.org/licenses/by-nc-nd/3.0/) which permits unrestricted noncommercial use, distribution, and reproduction in any medium, provided the original work is properly cited. Please cite this article as: Karaer E, Barut Ç. Study preferences in anatomy education: a descriptive study including preliminary results. Anatomy 2017;11(2):99-103. 